\title{
Evaluating biomass of Baltic filamentous cyanobacteria by image analysis
}

\author{
Roberta Congestri* ${ }^{*}$, Roberto Federici, Patrizia Albertano
}

Department of Biology, University of Rome 'Tor Vergata', Via della Ricerca Scientifica, 00133 Rome, Italy

\begin{abstract}
The biovolume of heterocystous cyanobacteria in the Central Baltic Sea was determined in natural, mixed-species samples by image analysis. Epifluorescence microscopy combined with computer-mediated image analysis was used to distinguish phycobiliprotein autofluorescent filaments of Anabaena, Aphanizomenon and Nodularia from other phytoplankters collected on membrane filters. A detailed description is given of the method based on the automatic measurement of single filament morphometry. Manual interactions and mathematical corrections were necessary during image processing to overcome filament overlapping and curvature on filters as well as the coiling of Nodularia spp.. The autofluorescence patchiness of Aphanizomenon sp. made it necessary to trace its dimensions manually. The data obtained were used to estimate variations in the vertical distribution of the biomass of the 3 cyanobacterial genera over a diel cycle.
\end{abstract}

KEY WORDS: Computer-mediated image analysis $\cdot$ Natural cyanobacterial populations $\cdot$ Filaments Biovolume $\cdot$ Baltic Sea

Resale or republication not permitted without written consent of the publisher

\section{INTRODUCTION}

In recent years, the need for automated methods to identify and quantify phytoplankton species in monitoring algal and cyanobacterial blooms has been increasing. Computer-mediated image analysis has been applied to enumerate the smallest phytoplankton fraction, the picoplankton, allowing morphometrical analysis and assessment of cell size distribution, as well as some taxonomic descriptions (Viles \& Sieracki 1992, Albertano et al. 1997). Although microscopical measurements provide the most accurate estimates of the dimensions and taxonomic traits, being virtually free of machine-based errors and of electronic noise (Hillebrand et al. 1999, Wheeler 1999), a variety of automatic methods have also been implemented. These include the use of parametric discriminants (McCall et al. 1996, Truquet et al. 1996), flow cytometry (Yentsch et al. 1983, Steen 1990), electronic particle counting (Boyd \& Johnson 1995) and microscopical

*E-mail: roberta.congestri@uniroma2.it image analysis (Krambeck et al. 1981, Estep et al.1986) for a rapid estimation of microbial cell size and abundance. However, quantification of filamentous species has always been problematic, and only few works have focussed on length determination and distribution of freshwater filamentous cyanobacteria; no automated estimation has ever been applied to trichome morphometry. Walsby \& Avery (1996) described a method based on epifluorescence microscopy for the total length measurement of the straight filaments of Oscillatoria (Planktothrix) rubescens and Anabaena flosaquae, both from culture and natural material. In their study, mathematical processes were described for correcting filament crossing and overlapping on optical fields. In addition, the use of a digitising tablet, which requires manual tracing by a computer and a mouse, was reported by Hoogveld \& Moed (1993).

In the present paper we describe a new technique for determining biovolume of individual taxa of filamentous cyanobacteria in natural water samples by means of epifluorescence microscopy combined with the Quantimet automatic system equipped with image analysis software. The epifluorescence microscopy 
system we used allowed us to distinguish heterocystous cyanobacteria in the presence of other phytoplankters on the membrane filters. Our method is based on the automatic estimation of trichome morphometry by calculating both the width and length of the single filaments. An accurate estimate of the biovolume of Anabaena, Aphanizomenon and Nodularia from natural Baltic population samples was thus obtained. The procedure included manual interactions and mathematical corrections to overcome the effects of filament coiling and overlapping along with Aphanizomenon autofluorescence patchiness. In order to assess the morphometry of coiled and/or curved cyanobacterial filaments, the images of coiled/curved trichomes were manually split insofar as to obtain a straight segment which was then automatically measured. This method allowed large stored sets of measurements of the filamentous cyanobacteria to be analysed at the genus level. This technique avoids the time-consuming use of a micrometer and decreases operator errors; it also reduces the exposure of the operator to toxic fixative.

We were able to estimate changes in the biovolume of Anabaena, Aphanizomenon and Nodularia over a diel cycle in net samples, collected during a summer cruise in the Central Baltic Sea in 1998.

\section{MATERIALS AND METHODS}

Field collections. Samples were collected on July $6-7,1998$, during a $24 \mathrm{~h}$ experiment at a drift station in the South Gotland Sea (Baltic Sea), 56 $16^{\prime} \mathrm{N}, 19^{\circ} 05^{\prime} \mathrm{E}$, on the RV 'Alexander von Humboldt' (Baltic Sea Research Institute, Warnemünde, Germany).

A $100 \mu \mathrm{m}$ mesh closing plankton net was towed vertically through the $0-7,7-14$ and $14-21 \mathrm{~m}$ depth layers at 04:00, 12:00, 20:00, 24:00 and 04:00 h (local time). Aliquots of concentrated seawater samples, each resulting from 10 net tows through the different depth intervals, were fixed on board in $2.5 \%$ glutaraldehyde, diluted in filtered seawater, and kept in $15 \mathrm{ml}$ tubes at $4^{\circ} \mathrm{C}$. A total of 15 samples were collected and transferred to the laboratory.

During the diel experiment, CTD (General Oceanics) profiles, which collected hydrographical data, were recorded simultaneously with the net catches.

Laboratory analysis. Filtration: In the laboratory, aliquots of fixed samples were diluted in distilled water and filtered onto black, $0.45 \mu \mathrm{m}$ pore-sized, $25 \mathrm{~mm}$ diameter Nucleopore filters, under vacuum below $7 \mathrm{kPa}$.

Epifluorescence microscopy and image recording: Membrane filters, mounted in immersion oil, were observed under epifluorescent illumination using a Leica Orthoplan microscope with a $25 \times$ objective,
$100 \mathrm{~W}$ mercury lamp and M2 green filter set (excitation wavelength $546 \mathrm{~nm}$, cut-off at $580 \mathrm{~nm}$ ). For each sample, epifluorescence images from 30 non-overlapping optical fields (located on a zed line), were transferred, after enhancing the brightness on dark background, to a high definition grey level camera (sensitivity of 0.0095 lux) Quantimet 970 (Cambridge Instruments) connected to a PC. The brightness setting was maintained constant during image acquisition, using the video camera facility 'Gain', for gain level, to standardise the procedure. Images were acquired, by means of Image ProPlus facility 'Acquire/Video-Digital' and stored as tif files (Fig. 1). Samples were processed within $5 \mathrm{wk}$ of collection in order to minimise autofluorescence loss.

Image processing and analysis: The procedure involves a series of commands and computer operations common to most image analysis software. In the present study Image ProPlus 3.0 for Windows software was used.

Before processing, images were calibrated to ensure that the subsequent measurements were stored in the corresponding dimensional units. The dimensions of a pixel in the images from the $25 \times$ objective were $p_{x}=p_{Y}$ $=2.81 \mu \mathrm{m}$. These values were saved in a calibration file to enter as constants into the image analysis (Measure, Calibration, Spatial). Before image processing, we defined a set of morphometrical parameters to be measured for each object detectable in the images, using the facility 'Parameter selection'. The following parameters were selected: area, minimum and maximum diameter, perimeter, minimum and maximum radius, size-width, size-length. This set was subsequently saved as a file to be loaded at the beginning of the process (Load settings).

Once an image was opened and the above files recalled, the procedure operated through 7 steps, some of which are shown in Fig. 2.

The contrast of the image was automatically enhanced by using 'Equalize/Best fit', to obtain good detection of the filaments/objects. Manual adjustment (Manual, Select ranges) was available in order to optimise the computer detection and highlight the objects below the machine threshold; this was crucial for the accuracy of the following morphometrical analysis. Since Anabaena, Aphanizomenon and Nodularia could have been present in the same image, each region of the image containing only 1 taxon was manually circumscribed by the command' Trace irregular AOI' (Area of Interest), as for the Nodularia filament shown in Fig. 2c. Every trichome present in the AOI was then automatically selected and highlighted in red, a number marked each of these objects. Then, using the facility 'Measure, Count/Size, Count', the set of selected parameters was calculated for these objects 

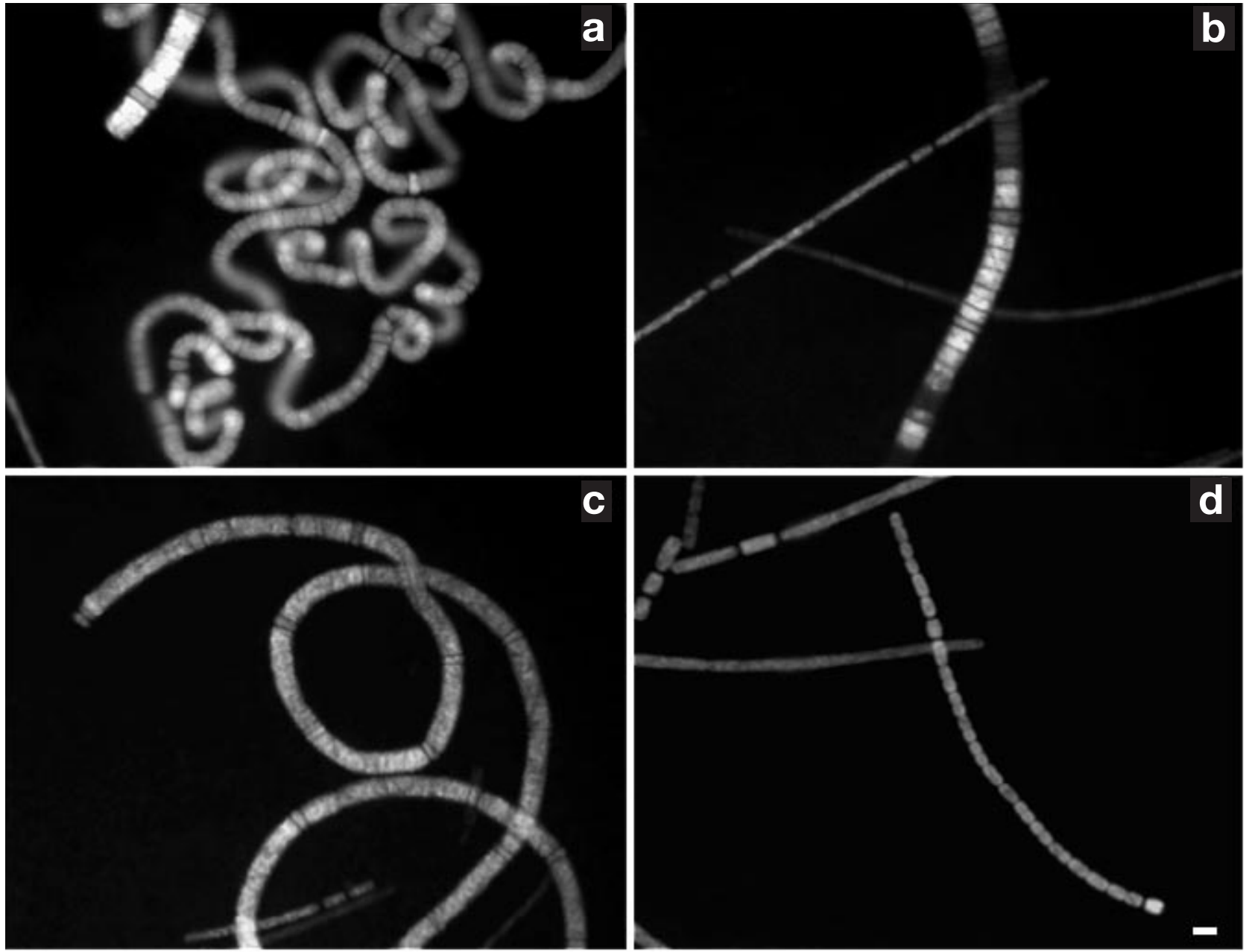

Fig. 1. Epifluorescence recorded images of (a) tightly coiled Nodularia ( $7.7 \mu \mathrm{m}$ in diameter), and part of a wider trichome (10.32 $\mu \mathrm{m})$; (b) slightly curved Nodularia (12.5 $\mu \mathrm{m}$ in width), and Aphanizomenon trichomes (4.00 $\mu \mathrm{m}$ in diameter); (c) spirally entangled Nodularia (10.4 $\mu \mathrm{m}$ in width); (d) a single Anabaena filament $(3.5 \mu \mathrm{m})$, and parts of Aphanizomenon trichomes. Scale bar $=10 \mu \mathrm{m}$

by the PC. This procedure was also repeated for Anabaena filaments. However, further manual interactions were required to correct problems linked to curvature and coiling, especially for Nodularia. Automatic measurements were not always adequate. Therefore, coiled filaments of Nodularia were manually split using the facility 'Edit, Split objects' in order to obtain sections as straight as possible (Fig. 2d). As for Anabaena, the same strategy was used to overcome the presence of pronounced constrictions at the crosswalls. Spurious highlighted objects were removed using the facility 'Hide'. All numerical data, figures and morphometrical measurements (maximum, minimum diameter, etc.) of individual filament or segments were eventually saved as .xls files (Save/Data to file). An Excel file retrieved from the PC measurements of a Nodularia filament, split into 6 segments, is shown in Table 1. The presence of overlapping areas required further manual and estimate corrections. Overlapping regions of Nodularia and Anabaena filaments, which appeared brighter because of the autofluorescence enhancement, were circumscribed by drawing additional lines so as to continue the outline of the filament. These regions, marked by additional numbers, were then added to the final calculation of the biovolume. Crossing and overlapping of filaments was initially decreased by diluting samples before filtration. The application of the procedure to Aphanizomenon trichomes did not produce the expected results, in that the trichomes were not detected as uniformly bright, although a $40 \times$ objective was used to improve autofluorescence resolution. Therefore, it was necessary to manually trace the lines matching the length and the width of each Aphanizomenon trichome using the function 'Measure, Measurements, Length'. Measurements were saved as .xls files as above. 

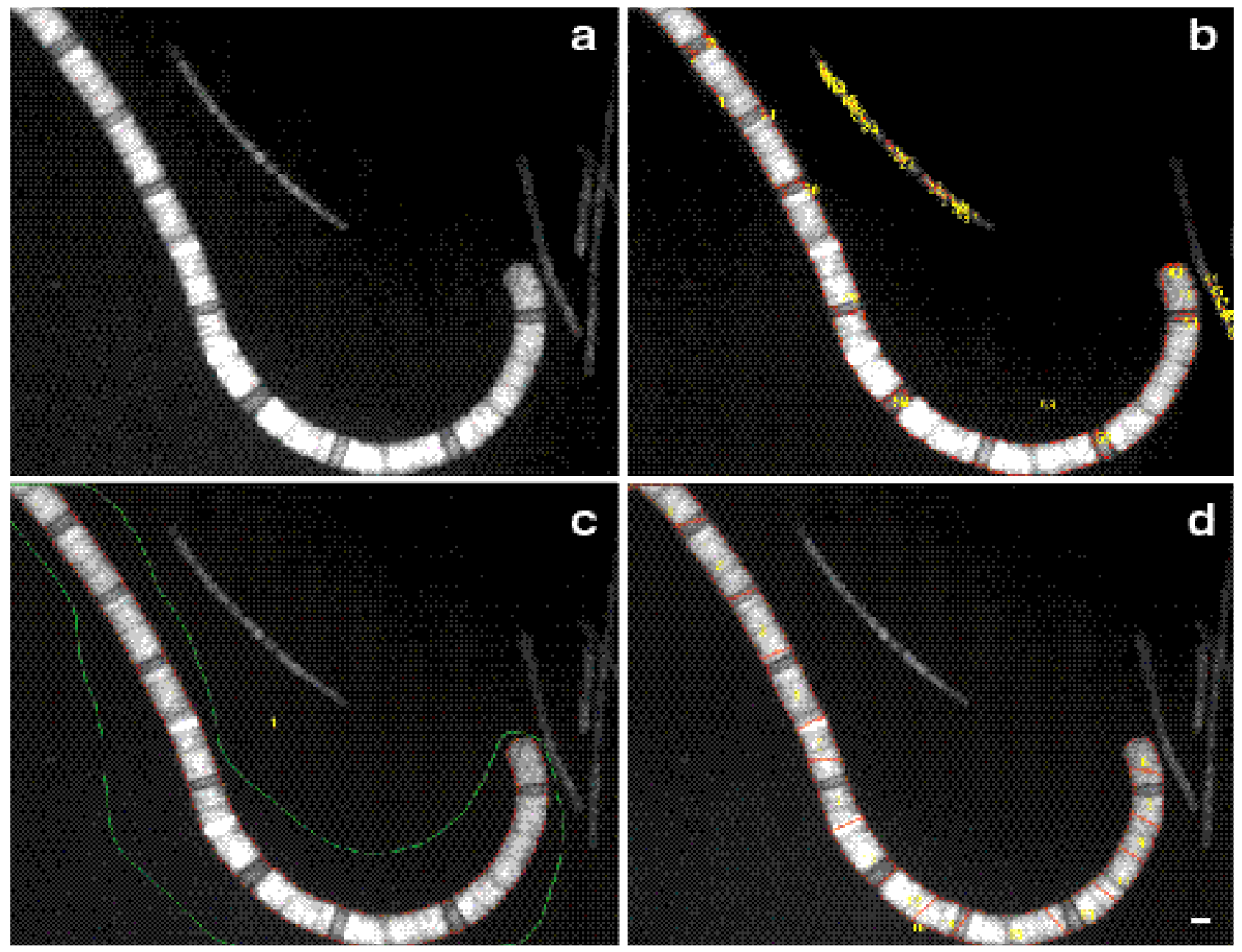

Fig. 2. Steps in the elaboration procedure of acquired epifluorescence images for the morphometrical evaluation of a single Nodularia filament. (a) Original recorded image, (b) automatic highlighting of all objects, (c) selection of Nodularia, and (d) manual splitting of the filament. Splitting lines were not traced at right angles in order to make them more visible in the figure. Scale bar $=10 \mu \mathrm{m}$

Determining biovolume: Biovolume determination was obtained by calculating the volume of a cylinder whose base diameter and length corresponded to minimum and maximum diameter respectively, measured by the PC for every trichome or section of trichome in the image. Minimum and maximum diameter were defined by the software as the length of the shortest and longest line joining 2 points of the object's outline and passing through the centroid.

To calculate the biovolume of a filament, the measurements of which are reported in Table 1, we divided the minimum diameter values by 2 to obtain the radii

Table 1. Excel file showing PC measurements of a Nodularia filament split into 6 segments

\begin{tabular}{|ccccccccc|}
\hline Object no. & Area & $\begin{array}{c}\text { Diameter } \\
\text { (max.) }\end{array}$ & $\begin{array}{c}\text { Diameter } \\
\text { (min.) }\end{array}$ & $\begin{array}{c}\text { Radius } \\
\text { (max.) }\end{array}$ & $\begin{array}{c}\text { Radius } \\
\text { (min.) }\end{array}$ & Perimeter & $\begin{array}{c}\text { Size } \\
\text { (length) }\end{array}$ \\
\hline (width) \\
\hline
\end{tabular}


of the base areas of the cylinders represented by each of the 6 segments and then calculated the area of these cylinder bases. Each area was then multiplied by the corresponding maximum diameter, to obtain the volumes of each of the 6 segments. These values were then summed to obtain the total biovolume of the filament. The biovolume of the different genera was thus calculated for each image and added to the remainder in the same sample in order to estimate the total biomass of the different taxa within the 3 water layers at the different sampling times (Table 2). The amount of Baltic water sampled during the net catches was calculated as equal to the volume of a cylinder, with the same base area of the mouth of the net and a length of $7 \mathrm{~m}$, corresponding to the depth interval sampled.
Table 2. Biovolume of the 3 cyanobacterial genera at different sampling times and depths

\begin{tabular}{|c|c|c|c|c|c|}
\hline $\begin{array}{l}\text { Time } \\
\text { (h) }\end{array}$ & $\begin{array}{l}\text { Depth } \\
\text { (m) }\end{array}$ & Nodularia & $\begin{array}{r}\text { Anabaena } \\
\left(\mu \mathrm{m}^{3}>\right.\end{array}$ & $\begin{array}{l}\text { Aphanizomenon } \\
10^{3} \mathrm{ml}^{-1} \text { ) }\end{array}$ & Biovolume $^{a}$ \\
\hline \multirow{3}{*}{ 04:00 } & $0-7$ & 69.4 & 1.2 & 96.6 & 167.2 \\
\hline & $7-14$ & 103.5 & 2.1 & 52.9 & 158.5 \\
\hline & $14-21$ & 43.6 & 2.3 & 39.1 & 85 \\
\hline \multirow{3}{*}{$12: 00$} & $0-7$ & 293.7 & 0.3 & 258.1 & 552.1 \\
\hline & $7-14$ & 131.3 & 1.6 & 148.2 & 281.1 \\
\hline & $14-21$ & 167.1 & 6.7 & 87.8 & 261.6 \\
\hline \multirow{3}{*}{ 20:00 } & $0-7$ & 141.7 & 7.6 & 220.1 & 369.4 \\
\hline & $7-14$ & 248.2 & 4.5 & 109.5 & 362.2 \\
\hline & $14-21$ & 273.6 & 3.8 & 135.1 & 412.5 \\
\hline \multirow{3}{*}{$24: 00$} & $0-7$ & 328.1 & 8.8 & 212.4 & 549.3 \\
\hline & $7-14$ & 214.6 & & 121.7 & 336.3 \\
\hline & $14-21$ & 21.1 & 2.6 & 48.1 & 71.8 \\
\hline \multirow{3}{*}{ 04:00 } & $0-7$ & 258.8 & 2.5 & 233.3 & 494.6 \\
\hline & $7-14$ & 208.8 & 11.5 & 141.6 & 361.9 \\
\hline & $14-21$ & 114.8 & 1.9 & 52.2 & 168.9 \\
\hline
\end{tabular}

\section{RESULTS AND DISCUSSION}

Image acquisition was the most critical step of the procedure. Therefore gain, offset adjustment and background correction were set at the beginning of the analysis and settings were maintained constant during the operations. This was necessary to achieve 'processable' images from mixed samples containing different autofluorescent organisms. Some advantage in image acquisition resulted from the immobilisation of filaments, all visible in a single focal plane onto the membranes. This minimised the 'halo' effects and the possible overestimation of the morphometrical parameters.

The present method was tested by comparing the measurements of the minimum diameter of Nodularia filaments obtained by image analysis to those calculated using the micrometer. From the 15 different samples collected onto membrane filters, 119 filaments were randomly selected. After measuring the filament diameter with a micrometer, the same trichomes were recorded as tif images and automatically processed. Statistical analysis showed a mean value of $10.85 \mu \mathrm{m}$ ( $\mathrm{SD}=2.36$ and $\mathrm{SE}=0.22 \mu \mathrm{m}$ ) for the microscopical measurements and $10.33 \mu \mathrm{m}(\mathrm{SD}=3.11$ and $\mathrm{SE}=0.28 \mu \mathrm{m})$ for the automatic estimates. A $t$-test for equality of means was performed: no significant discrepancy was observed between the 2 sets of measurments $(t=1.459$, $\mathrm{df}=236$ and $\mathrm{p} \leq 0.146)$. Nodularia was selected for the test because it is the most difficult to automatically analyse due to filament coiling or curvature. Out of the
3 coexisting cyanobacterial genera, collected on filters from natural water samples, only Aphanizomenon could not be analysed by implementing a fully automatic analysis. Nevertheless, a validation of computermediated image analysis techniques for straight cyanobacterial filaments has been proposed and thoroughly discussed by Walsby \& Avery (1996).

About 450 images were processed to assess individual genus contribution to cyanobacterial standing stock in the $>100 \mu \mathrm{m}$ size fraction over a night-day cycle, the night period lasting about $5 \mathrm{~h}$, from 23:00 to 04:00 h, in Central European Summer Time at the sampling site. Changes in the vertical distribution of total biovolume of the diazotrophic cyanobacterial assemblage were analysed over the $24 \mathrm{~h}$ cycle (Fig. 3). A subsurface (0 to $14 \mathrm{~m}$ ) accumulation occurred early in the morning. Total biovolume peaked $\left(552 \times 10^{3} \mu \mathrm{m}^{3} \mathrm{ml}^{-1}\right)$ in the 0 to $7 \mathrm{~m}$ layer at noon and a general increase occurred in the 7 to $21 \mathrm{~m}$ water mass. A surface decrease was calculated in the afternoon, while concentrations doubled in depth samples. A rather marked increase followed between 20:00 and 24:00 h at the surface layer only, with a value close to the peak $\left(549 \times 10^{3} \mu \mathrm{m}^{3} \mathrm{ml}^{-1}\right)$, while a considerable decrease was recorded in the 7 to $21 \mathrm{~m}$ water layer. Concentration showed a slight decrease in the 04:00 $\mathrm{h}$ record at the surface layer, while higher values occurred in the 2 deepest layers. The vertical distribution and fluctuation of Anabaena, Aphanizomenon and Nodularia concentrations were analysed in detail (Figs. $4,5 \& 6$ ). A subsurface ( 0 to $7 \mathrm{~m}$ ) biovolume max- 
imum was shown by Nodularia (Fig. 4) at noon and midnight, the amount at 24:00 $\mathrm{h}$ being higher, whereas an opposite trend was measured in depth samples from 7 to $21 \mathrm{~m}$, where the maximum biomass occurred at 20:00 h. The vertical distribution of Anabaena (Fig. 5) showed subsurface accumulation in the samples collected during the second half of the day. The maximum concentration was calculated to be in the intermediate water layer, where a peak was detected at 04:00 h, following very low or moderate concentrations. At the deepest layer, high concentrations occurred at noon. Aphanizomenon (Fig. 6), which also showed subsurface accumulation, had similar diel trend within the 2 uppermost sampled intervals, from surface down to $14 \mathrm{~m}$, with peak densities occurring at noon, followed by almost comparable levels at 04:00 h. The maximum biomass occurred at 20:00 h within the 14 to $21 \mathrm{~m}$ layer.

Anabaena, Aphanizomenon, and Nodularia populations were dispersed rather homogeneously throughout the water column. The records, at different times within single depth intervals, showed marked fluctuations for all 3 genera, suggesting that there was vertical water mixing and flotation provided by the gas-vesicles present in these filamentous taxa (Walsby et al. 1995). The temperature and salinity profiles (Fig. 7) indicated a completely mixed condition (temperature variation $<0.2^{\circ} \mathrm{C}$ ) from the top layer down to a depth of about $15 \mathrm{~m}$ over the whole sampling period; this condition was probably responsible for the up and down circulation of filaments and their fairly homogeneous dispersal throughout the water column. When compared to the other genera, the higher subsurface concentration of Aphanizomenon in the light period cannot be explained by a faster upward migration by floating, which has been shown to occur during stable water column conditions (Walsby et al. 1997). Alternatively, differences in the size and age of Aphanizomenon colonies and Nodu-

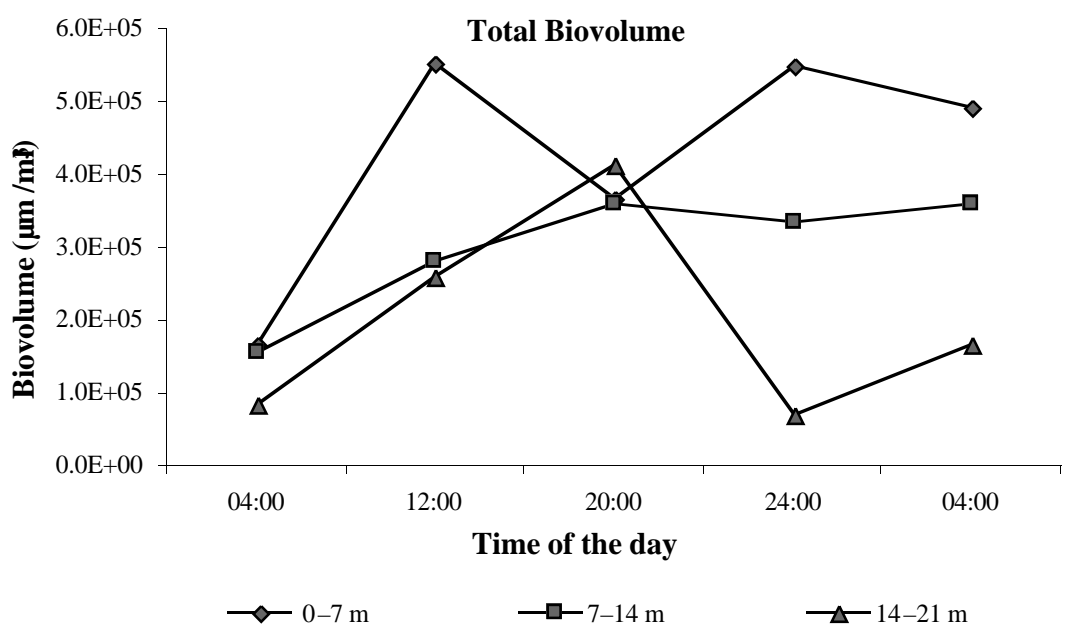

Fig. 3. Total biovolume fluctuation of diazotrophic cyanobacteria, over the diel cycle, at the different sampling depth layers

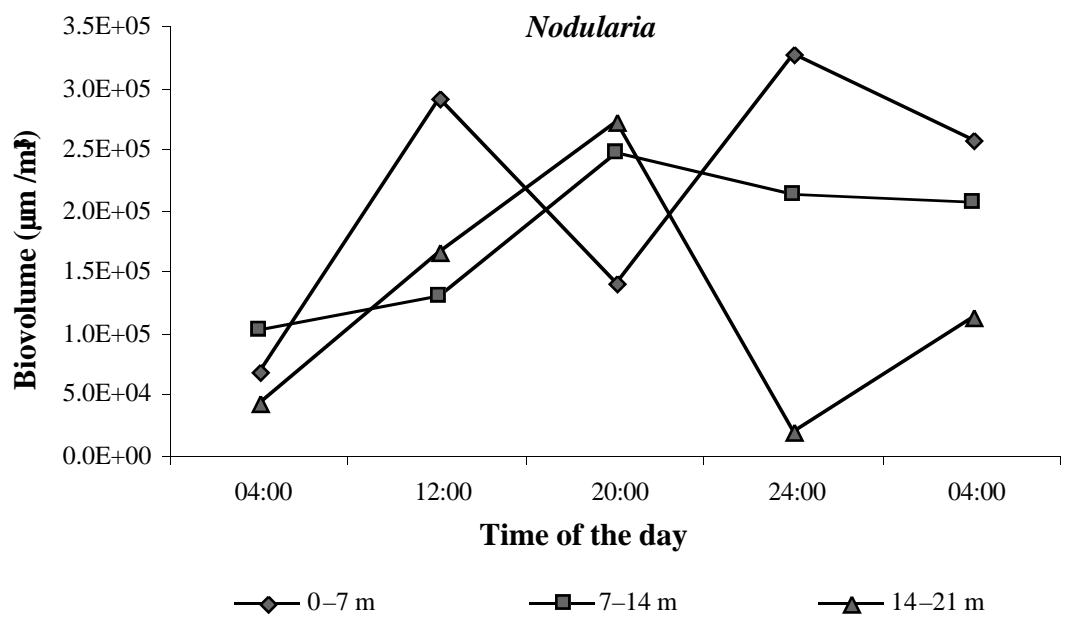

Fig. 4. Diel variation of Nodularia biovolume at the different sampling depth layers

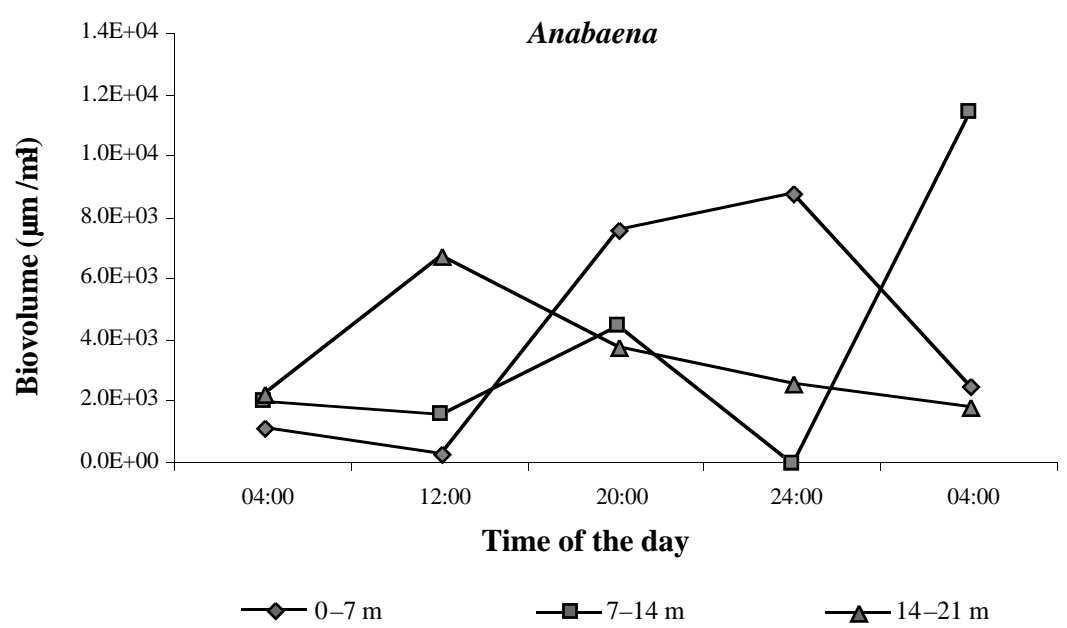

Fig. 5. Diel variation of Anabaena biovolume at the different sampling depth layers 
laria aggregates could have affected their vertical distribution (Walsby et al. 1995). The salinity profile, which varied by only 0.001 to 0.002 PSU from surface to $15 \mathrm{~m}$, indicated that the same water mass was analysed at the drift station, and that the same diazotrophic populations were followed.

These data could not provide enough information on growth, a possible sampling error or the vertical migration to and from below $21 \mathrm{~m}$ of depth; therefore, the changes in biomass observed during the $24 \mathrm{~h}$ cycle could not be accounted for. In any case, a net sampling strategy cannot provide a reliable evaluation of phytoplankton distribution at each depth.

Our aim was to show an application of this imageanalysis-based method to precisely assess microbial biomass in natural water samples. In fact, even the most recent literature on filamentous cyanobacterial concentrations in the Baltic Sea reported the biomass in terms of number of colonies per volume units, irrespective of the variabiliy of the number of filaments in the colony itself (Walsby et al. 1997). Other estimates were based on the length of the filaments assuming a constant C content per length unit (Edler 1979, Walsby et al. 1995, 1997, Kononen et al. 1996). This estimation did not take into account the variability in the filament width that trichomes, even those belonging to the same species, can present. This was the case for Nodularia, which, in the present study, showed a large variation in filament diameter. In order to distinguish different 'morphometrical types' in terms of filament diameter, the Nodularia dataset can be statistically analysed and thus may result in further exploitation of the method.

\section{Temperature $\left({ }^{\circ} \mathrm{C}\right)$}

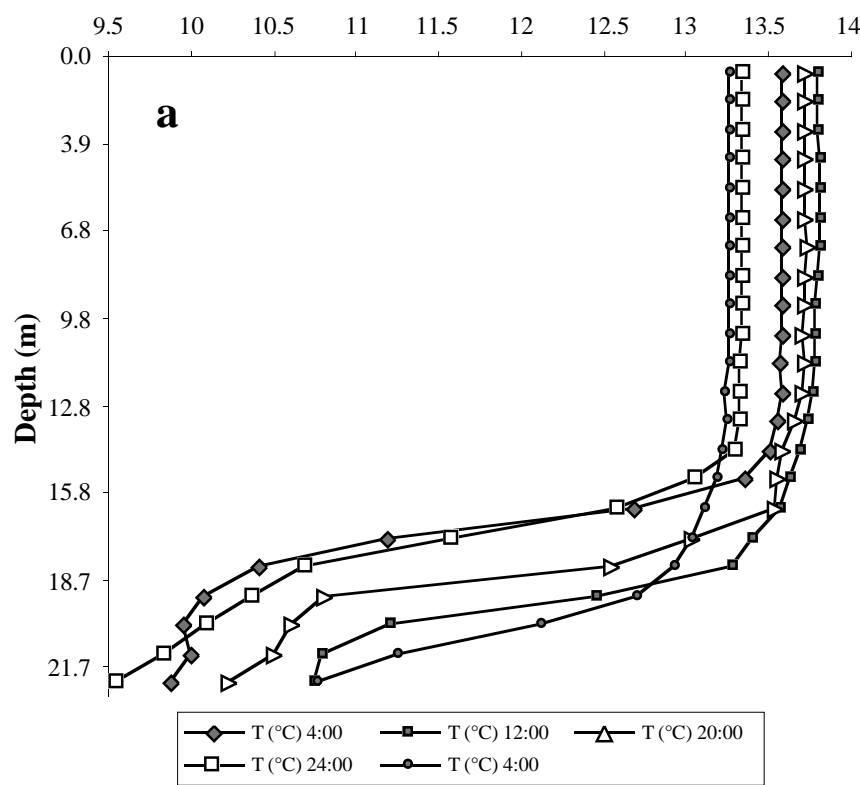

Salinity (PSU)

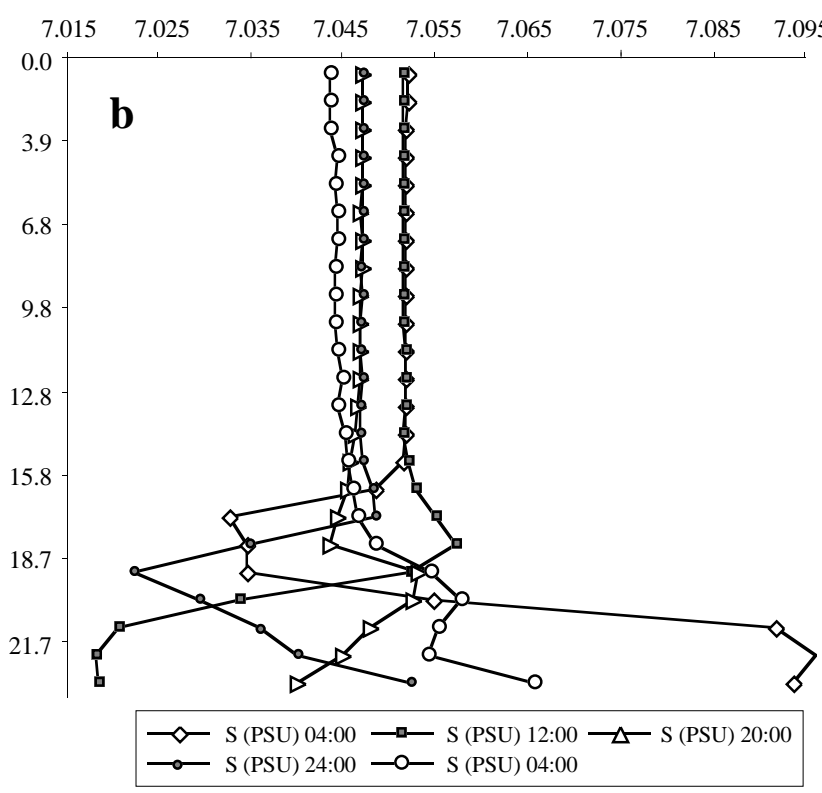

Fig. 7. (a) Temperature and (b) salinity vertical profiles recorded on July 6-7, 1998, over a diel cycle in the Central Baltic Sea 
Acknowledgements. We gratefully thank Dr Klaus von Broeckel (Institut für Meereskunde an der Universität Kiel, Germany) for organising the cruises and making available physicochemical data, Dr Palma Mattioli for her skillful assistance during image analysis processing and Dr Maria Lo Ponte for improving the English manuscript. This work is a contribution to the European Union ELOISE Programme (ELOISE No. 166) in the framework of the BASIC project carried out under contract ENV4-CT97-0571.

\section{LITERATURE CITED}

Albertano P, Di Somma D, Capucci E (1997) Cyanobacterial picoplankton from the Central Baltic Sea: cell size classification by image-analyzed fluorescence microscopy. J Plankton Res 19:1405-1416

Boyd CM, Johnson GW (1995) Precision of size determination of resistive electronic particle counters. J Plankton Res 17: 41-58

Edler L (1979) Recommendations on methods for marine biological studies in the Baltic Sea: phytoplankton and chlorophyll. The Baltic Marine Biologists, Malmö (SE)

Estep KW, MacIntyre F, Hjörleifsson E, Sieburth JM (1986) MacImage: a user friendly image-analysis system for the accurate mensuration of marine organisms. Mar Ecol Prog Ser 33:243-253

Hillebrand $\mathrm{H}$, Duürselen CD, Kirschtel D, Pollingher U, Zohary $T$ (1999) Biovolume calculation for pelagic and benthic microalgae. J Phycol 35:403-424

Hoogveld HL, Moed JR (1993) A digitising tablet for determining the length distribution of filamentous cyanobacteria. Eur J Phycol 28:59-61

Kononen K, Kuparinen J, Mäkelä K, Laanemets J, Pavelson J, Nõmmann S (1996) Initiation of cyanobacterial blooms in a frontal region at the entrance to the Gulf of Finland, Baltic Sea. Limnol Oceanogr 41(1):98-112

Editorial responsibility: William Li, Dartmouth, Nova Scotia, Canada
Krambeck C, Krambeck HJ, Overbeck J (1981) Microcomputer-assisted biomass determination of plankton bacteria on scanning electron micrographs. Appl Environ Microbiol 42:142-149

McCall H, Bravo I, Lindley JA, Reguera B (1996) Phytoplankton recognition using parametric discriminants. J Plankton Res 18:393-410

Steen HB (1990) Characters of flow cytometers. In: Melamed MR, Lindmo T, Mendelsohn D (eds) Flow cytometry and sorting, 2nd edn. Wiley-Liss, NewYork, p 11-25

Truquet P, Lassus P, Honsell G, Le Déan L (1996) Application of a digital pattern recognition system to Dinophysis acuminata and D. sacculus complexes. Aquat Living Resour 9: 273-279

Viles CL, Sieracki ME (1992) Measurement of marine picoplankton cell size by using a cooled, charge-coupled device camera with image-analyzed fluorescence microscopy. Appl Environ Microbiol 58:584-592

Walsby AE, Avery A (1996) Measurement of filamentous cyanobacteria by image analysis. J Microbiol Methods 26: $11-20$

Walsby AE, Hayes PK, Boje R (1995) The gas vesicles, buoyancy and vertical distribution of cyanobacteria in the Baltic Sea. Eur J Phycol 30:87-94

Walsby AE, Hayes PK, Boje R, Stal LJ (1997) The selective advantage of buoyancy provided by gas vesicles for planktonic cyanobacteria in the Baltic Sea. New Phytol 136:407-417

Wheeler PA (1999) Cell geometry revisited: realistic shape and accurate determination of cell volume and surface area from microscopic measurements. J Phycol 35: 209-210

Yentsch CM, Horan PK, Dortch Q, Haugen E, Legendre L, Murphy LS, Perry MJ, Phinney DA, Pomponi SA, Spinrad RW, Wood M, Yentsch CS, Zahuranec BJ (1983) Flow cytometry and cell sorting: a technique for analysis and sorting of aquatic particles. Limnol Oceanogr 28: $1275-1280$

Submitted: April 11, 2000; Accepted: August 11, 2000 Proofs received from author(s): October 5, 2000 